\title{
PHILOSOPHY AND POLICY GOVERNING RESEARCH BY ONTARIO DEPARTMENT OF LANDS AND FORESTS
}

\author{
By G. H. BAYLY ${ }^{1}$
}

I shall make it clear from the outset that while most members of this panel are Research Scientists, I am not and therefore I cannot claim to speak with the authority of a Research Scientist on the matters we are discussing. I am an administrator whose administrative duties involve him in certain research matters, and therefore I must admit to seeing research with the eyes of an administrator and not the objectivity of a Research Scientist.

A few years ago a departmental committee was set up for the purpose of assessing objectives and programmes of research in the Ontario Department of Lands and Forests. I shall attempt to sketch the result of this assessment, because in a sense they summarize the Department's composite view of research.

The objective of research in the Department is the acquisition of knowledge directed towards improving management of natural resources by the Department. We do not do research for its own sake, but rather to provide the answers to technical problems of importance to the staff responsible for resource management. With this in mind, it seems logical that evaluation of current and proposed departmental research programs should be based on the following criteria:

First-What information is needed for conduct of resource management work?

Secondly-What is the estimated cost of a research program in relation to the value of the information the resource managers expect from it?

Thirdly--Can we get the money and staff needed for the programme?

Resource management is the main function of the Department and it seems reasonable that departmental research should play a substantial supporting role.

The Department has found it advantageous to co-operate in research programs with other agencies such as the University of Toronto, the woodusing industries, the Ontario Research Foundation and the Research branches of the Federal Department of Forestry.

\footnotetext{
${ }^{1}$ Assistant Deputy Minister, Dept. of I.ands and Forests, Toronto, Ont.
} 
Suggestions have been made that because our research objectives are relatively short-range in nature and the objectives of other organizations such as universities and the federal government are generally more longrange in nature, that we should concentrate on short-term or applied research, leaving the long-term or fundamental research areas to the other research organizations. Although this proposal has some attractive features, we have found over the years that it has not been practicable to put it into effect except in a very general way. The allocation of programs to a research organization, or selection of programs by it, usually depends on the location and suitability of staff for a project and the availability of funds and necessary facilities.

The matter of centralization or decentralization of research work has been the subject of a good deal of debate in past years in our Department. On the one hand there is the argument that forest research should take place in the forest. It is hard to move a mature tree or a moose into a laboratory in Southern Ontario. On the other hand, as we study many different forest types and fish and wildlife species which are located in widely separated parts of the Province, decentralization involves scattering people and buildings around rather widely. We also hear the argument, particularly from the research workers themselves, that the climate is most favourable for productive and valuable work when research workers have frequent exposure to each other. In other words, research should be centralized. On the whole we have followed the latter course, although not completely. The bulk of our research workers have their headquarters at the Southern Research Station at Maple. A large minority, particularly in fisheries research, is permanently located at a few small stations across the Province.

As I expect to be asked a question later about our publications policy, I shall say at this time only that it has been a much discussed matter in the Department as to whether our research results should all be published in scientific journals, or in department papers and publications. I think, such discussions have been a common experience in government research organizations where the objective of the organization is the improvement of management and operating practices. Rightly or wrongly we have often used the less formal channels and much departmental research has not been seen in scientific journals.

Being a department with a rather wide range of functional responsibilities, it is understandable that the emphasis on research programs should follow several different courses. Using as a criterion the expenditure on research in three different fields, I find that we emphasize almost equally forestry and fisheries research. Wildlife receives much less emphasis. In forestry research we stress silviculture, particularly of spruce and pine, the species of most commercial importance to the Province. 